\title{
3D Finite Elements Modelling for Design and Performance Analysis of $\mathrm{UO}_{2}$ Pellets
}

\author{
Gustavo L. Demarco ${ }^{1,2}$ and Armando C. Marino ${ }^{1,3}$ \\ ${ }^{1}$ Gerencia Ciclo del Combustible Nuclear (GCCN), Centro Atómico Bariloche (CAB), Comisión Nacional de \\ Energía Atómica (CNEA), R8402AGP Bariloche, Argentina \\ ${ }^{2}$ Facultad Regional Villa María, Universidad Tecnológica Nacional, Av. Universidad 450, X5901ATH Villa María, Argentina \\ ${ }^{3}$ Instituto Balseiro (IB), Universidad Nacional de Cuyo, Centro Atómico Bariloche (CAB), R8402AGP Bariloche, Argentina \\ Correspondence should be addressed to Armando C. Marino, marino@cab.cnea.gov.ar
}

Received 18 August 2010; Accepted 18 December 2010

Academic Editor: Juan Ferreri

Copyright (C) 2011 G. L. Demarco and A. C. Marino. This is an open access article distributed under the Creative Commons Attribution License, which permits unrestricted use, distribution, and reproduction in any medium, provided the original work is properly cited.

The geometry of a fuel pellet is a compromise among the intention to maximize $\mathrm{UO}_{2}$ content and minimize the temperature gradient taking into account the thermomechanical behaviour, the economy, and the safety of the fuel management during and after irradiation. "Dishings", "shoulders", "chamfers", and/or "a central hole" on a cylinder with an improved $l / d$ relation (length of the pellet/diameter) are introduced in order to optimize the shape of the pellet. The MeCom tools coupled with the BaCo code constitutes a complete system for the 3D analysis of the stress strain state of the pellet under irradiation. CANDU and PHWR MOX fuel will be used to illustrate the excellent qualitative agreement between experimental data and calculations by using these computational tools.

\section{Introduction}

A fuel element is a set of fuel rods assembled with structural components like "grids" and "spacers." Each fuel rod is a Zircaloy-made tube (or "cladding") filled with $\mathrm{UO}_{2}$ pellets. The fuel pellet is axisymmetric with a geometry optimized to take into account the thermo-mechanical behaviour during irradiation at the nuclear power plant.

The starting point for the design of $\mathrm{a} \mathrm{UO}_{2}$ pellet is a simple cylinder. However, due to the temperature profile developed under irradiation, this shape evolves to a "bamboo" shape. The $l / d$ relation (length of the pellet/diameter) is optimized in order to minimize that geometric behaviour. A few modifications in the cylinder are introduced in order to reduce the pellet to pellet axial stresses and the PCMI (pelletcladding mechanical interaction) mainly at the top and at the bottom of the cylinder. Those stresses are reduced by using "dishings", "shoulders," and "chamfers" in the cylinder. In fact, stresses are reduced by sectioning the parts of the pellet where the maximum deformations are present. Such a modified pellet becomes an optimized $\mathrm{UO}_{2}$ pellet. These new designs are tested irradiating normal and unusual pellet shapes. The study of conics, flat, and/or hollow pellets under irradiation was presented in several papers along with the study of the relative influence of the variation of $l / d$ and the size of dishing, chamfer, and shoulder $[1,2]$. The goal is to maximize the $\mathrm{UO}_{2}$ content, minimize the temperature profile, and reduce the effect of PCMI and PCI-SCC (pellet cladding interaction-stress corrosion cracking) taking into account the economy and the safety of the fuel management during and after irradiation.

Diameter gauge measurements have revealed the presence of increased dimensions at the position of pellet ends during and after power ramps resulting from the wheat sheaf of hourglass or bamboo shape adopted by the pellets. A detailed diameter measurement reveals the presence of a secondary ridge at the middle of the pellet [3]. The change is on account of the poor thermal conductivity of the $\mathrm{UO}_{2}$ fuel and the consequent differential thermal expansion caused by the temperature difference between the interior and exterior of the pellets. A good example of the pellet diameter change during power ramp will be presented bellow. Ridge 
formation to a greater or lesser extent is found in all small gap rods when power ramped. The axial displacement of the pellets and the axial variation of the power profile in long fuels as PWR and BWR could lead to the formation of ridges at different heights of the rod (racketing). The small length of CANDU and experimental fuel rods guarantees a good positioning of pellet ends with the ridge due to the absence of racketing. We could expect the presence of clear ridges in these types of fuels when the gap is closed by power ramping, swelling, creepdown, or a combination of them. This particular situation is the usual condition under irradiation for the CANDU fuel rods where the cladding is collapsible and no gap is present.

The thermo-mechanical behaviour of a nuclear fuel rod under irradiation is a complex process where many coupled physical and chemical phenomena are present. The BaCo code ("BArra COmbustible", Spanish expression for "fuel rod") was developed at the Atomic Energy National Commission of Argentina (CNEA, "Comisión Nacional de Energía Atómica") for the simulation of the behaviour of nuclear fuel rods under irradiation. BaCo uses a quasi-two-dimensional approach. With its use, several 3D (three-dimensional) topics as the stress-strain state can be explained. Nevertheless, the BaCo code results are enhanced by using "ad hoc" tools based on a finite elements scheme developed at the MECOM and DAEE Divisions (Bariloche Atomic Centre, CNEA). The temperature profile and the boundary conditions, among others, are calculated with BaCo to be inserted as input data in the MECOM tools. Then, the 3D stress-strain state and the deformations of the $\mathrm{UO}_{2}$ pellet are calculated. The MECOM tools include the same laws for elasticity and thermal expansion as the BaCo code. The shape of the pellet under irradiation showing the stress profile, the bamboo effect, and other 3D effects, as the presence of the secondary ridge and the radial profile of a fuel rod, can be observed with the MECOM tools.

In this paper, the symbiosis between MECOM tools and BaCo by using CANDU and PHWR MOX fuels as input data is shown. The results show good agreement between experimental data and calculations mainly for the pellet radial profile after irradiation. The coupling between BaCo and MECOM tools constitutes a powerful system for the analysis and design of nuclear fuel pellets taking into account the best combination for $l / d$ and the dimensioning of dishing, shoulder, and chamfers. Innovative or unusual pellet shapes can be analyzed by using these "ad hoc" tools.

The BaCo code structure and models have already been described in [4], including steady state and transient thermal analysis. The data postprocessing and the coupling with $3 \mathrm{D}$ calculation using finite elements (called PosBaCo) improve the output of $\mathrm{BaCo}$ and the analysis of results.

\section{MeCom Tools}

The package "acdp95" includes tools for mesh generation and optimization and a complete collection of visualization programs [7]. Nonstructured meshes composed of tetrahedral elements for arbitrary geometries can be obtained.

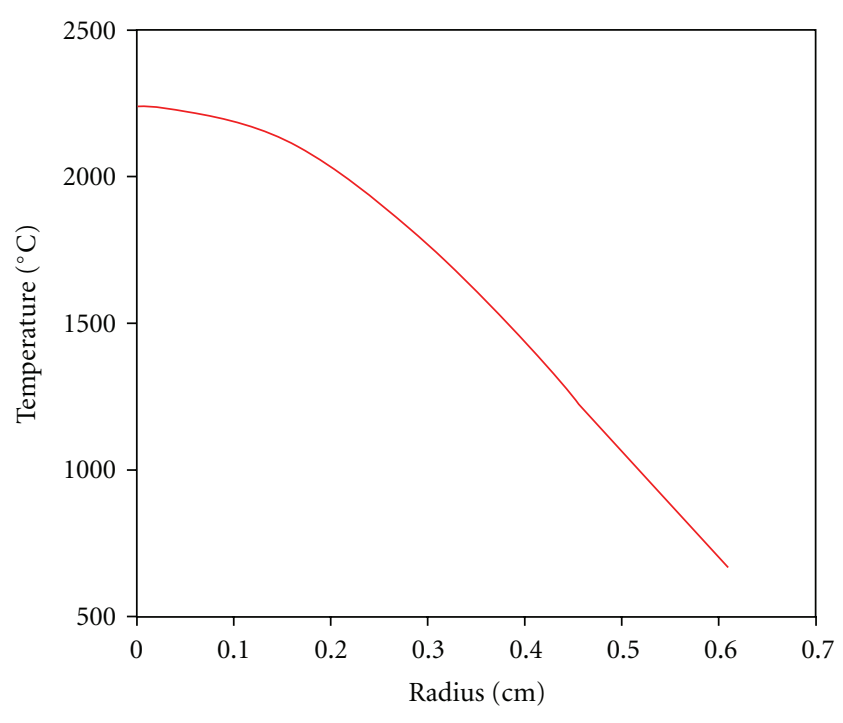

FIgURE 1: CANDU pellet temperature profile.

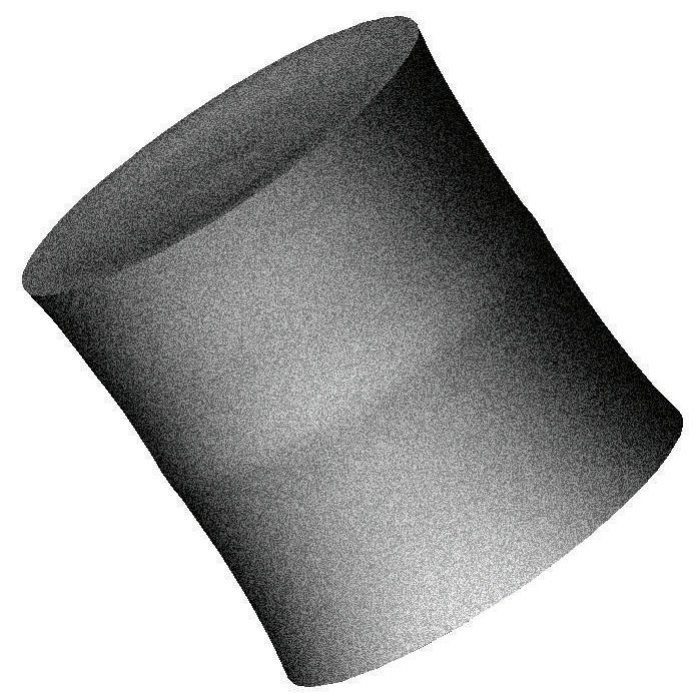

Figure 2: 3D CANDU pellet calculated with $\mathrm{BaCo}+\mathrm{MeCom}$ Tools. Radial deformations are emphasized.

Visualization tools for viewing meshes and the FEM solutions over these meshes (scalar and vectorial) are available.

The 3D finite element (FEM) calculations were performed with a set of tools developed at the Computational Mechanics (MeCom) Division at the Bariloche Atomic Centre (CAB), CNEA. Basically, these are grouped in two software packages, "acdp95" [5] and "gpfep99" [6], kindly made available to us by its main developers.

The package "gpfep99" is a system to generate FEM solvers. It is distributed in source form (written in FORTRAN 77). It is up to the user to write a subroutine that implements the elemental matrix for the problem at hand. In our case, we wrote no more than three hundred lines of code (100 for the elasticity problem, 100 for the stress calculation, 


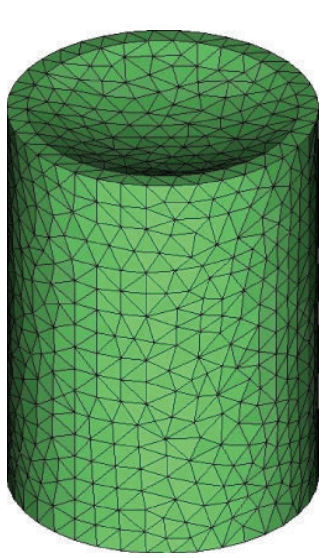

(a)

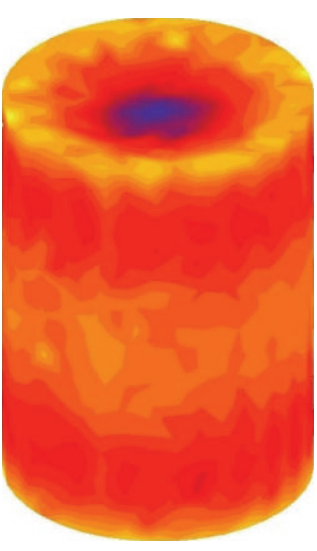

(b)

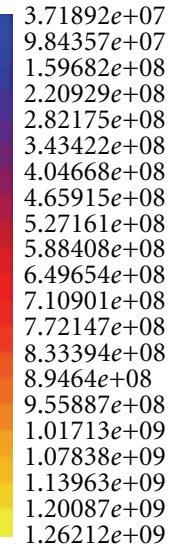

$1.26212 e+09$

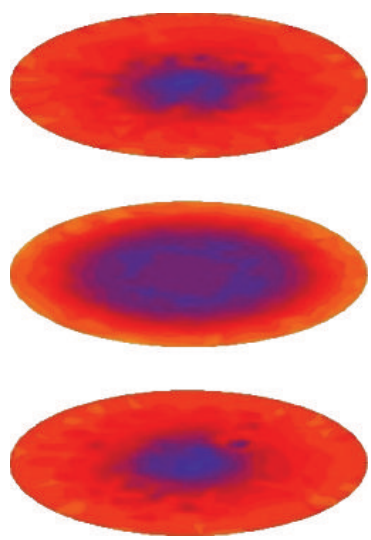

(c)

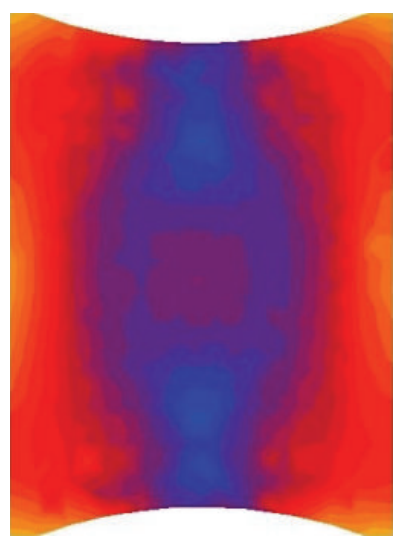

(d)

FIGURE 3: Mesh and von Mises equivalent stress of the pellet. (a) Unstructured mesh for finite elements calculation. (b) 3D view of the von Mises equivalent stresses. (c) Three horizontal sections of the von Mises stress field. (d) Vertical section through the symmetry axis of the von Mises stress field.

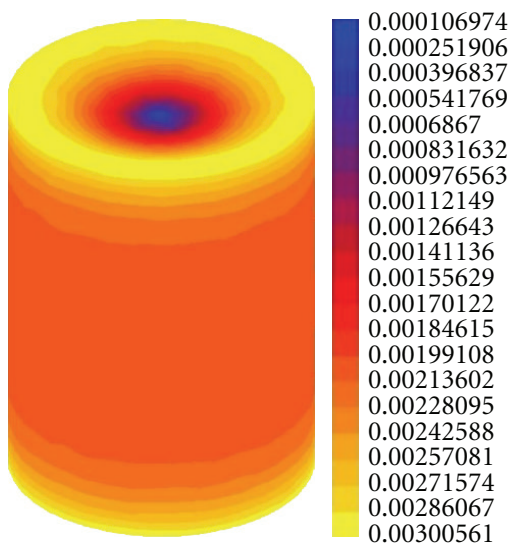

(a)

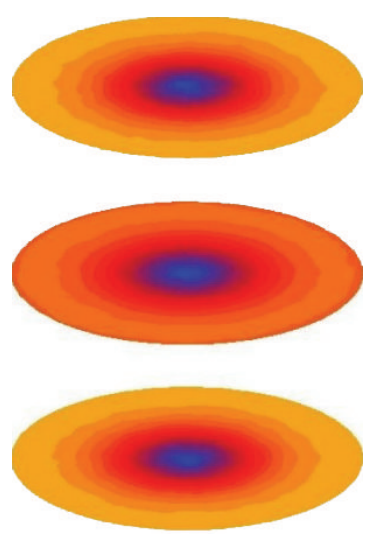

(b)

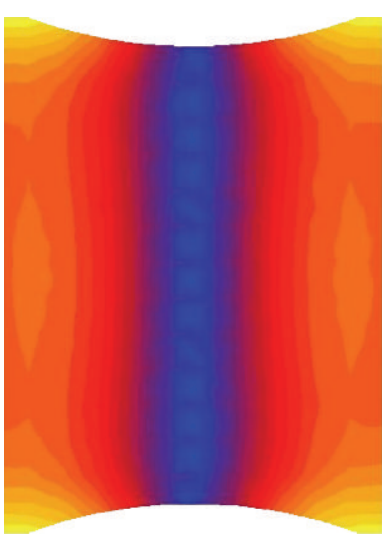

(c)

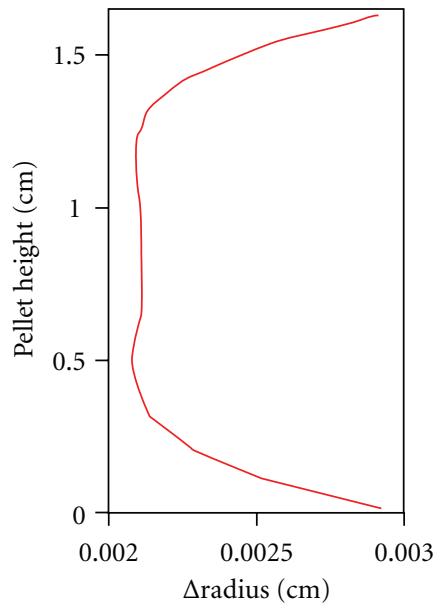

(d)

FIgURE 4: Radial deformations in a CANDU fuel pellet. (a) 3D view of the radial deformations. (b) Three horizontal sections of the radial deformation field. (c) Vertical section through the symmetry axis of the radial deformation field. (d) Radial deformation along a cylinder generatrix. 


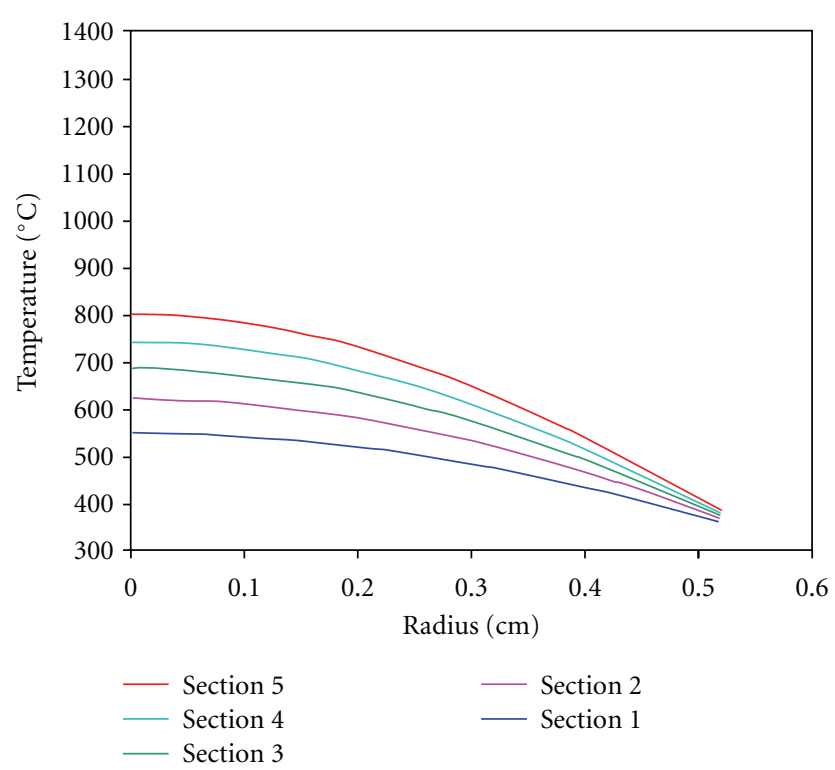

FIgURE 5: Temperature profile of the MOX fuel A.1.3 before ramping at EOL (Section 1 at the bottom of the fuel rod).

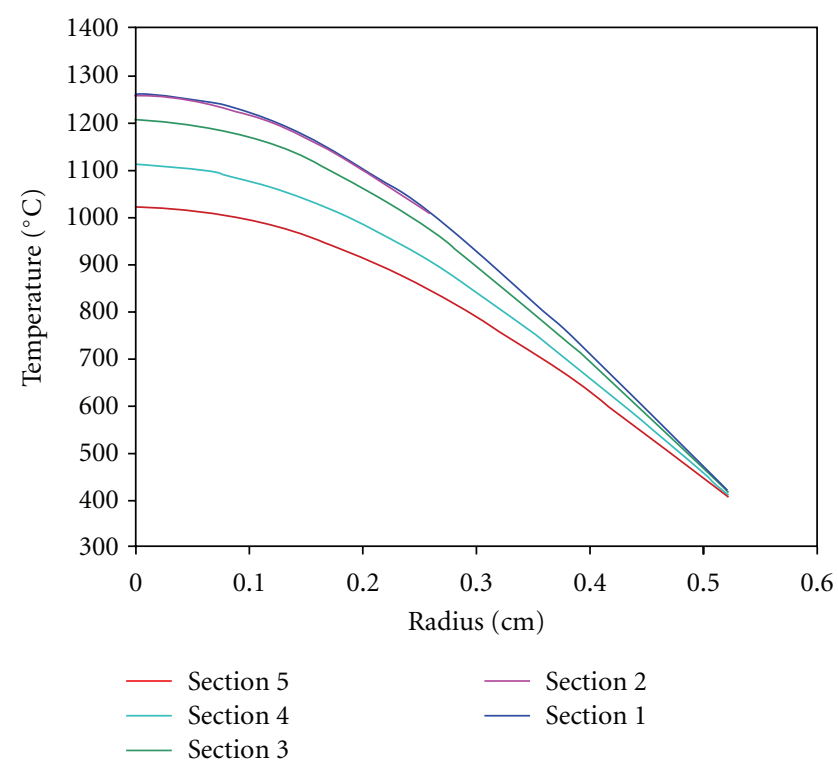

Figure 6: Temperature profile of the MOX fuel A.1.3 at the top power ramp at EOL (Section 1 at the top of the fuel rod due to the flipping before ramping).

and 100 for the von Misses stress calculation). "gpfep99" can handle time-dependent and nonlinear problems, and there are several types of elements (not only linear tetrahedral) implemented. There is also a parallel version [8]. The solutions obtained with "gpfep99" can be visualized with the "acdp95" tools.

For the linear elasticity problem, the "gpfep99" package obtains the finite element approximation corresponding to the given input mesh (generated with the "acdp95" package) and the following differential equation:

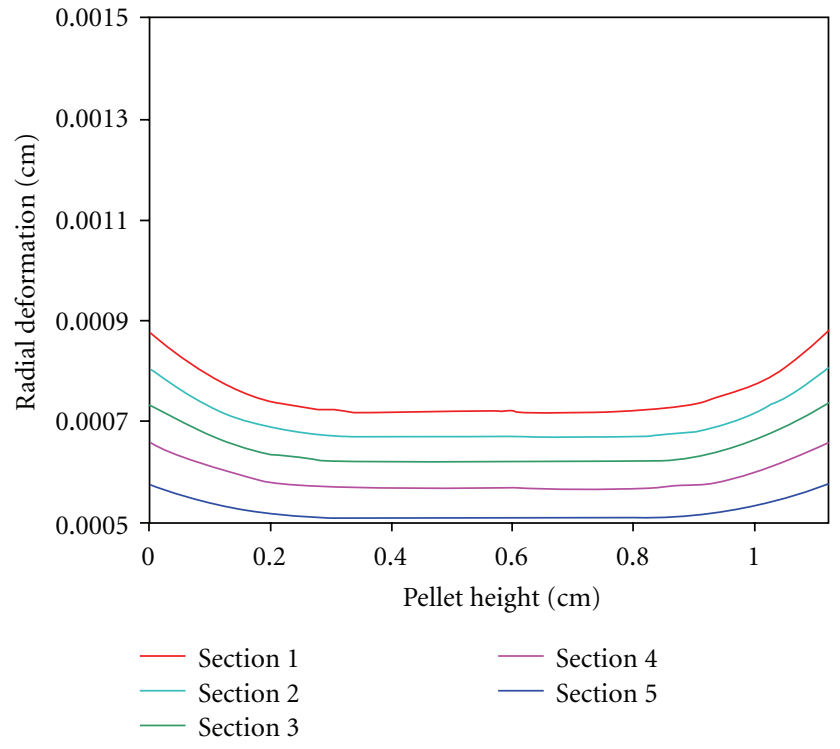

Figure 7: Pellet profile of five axial sections of the MOX fuel A.1.3 before ramping at EOL.

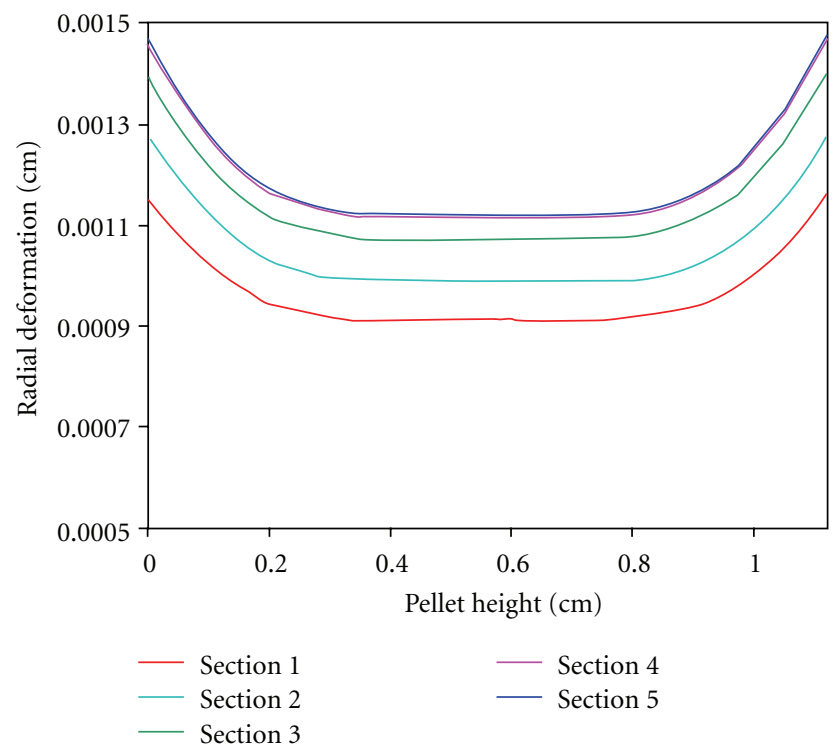

Figure 8: Pellet profile of the five axial sections of the MOX fuel A.1.3 at the top power ramp at EOL.

$$
\partial_{j} \sigma_{i j}=0,
$$

where $\sigma_{i j}$ is the stress tensor given by

$$
\sigma_{i j}=\lambda(\nabla \vec{u}) \delta_{i j}+\mu\left(\partial_{j} u_{i}+\partial_{i} u_{j}\right)-K \alpha \cdot\left(T-T_{0}\right) \delta_{i j},
$$

where $\lambda$ and $\mu$ are the Lamé coefficients, $K$ is the compression modulus, $T_{0}$ is the reference temperature, $\alpha$ is the thermal expansion coefficient, and $\vec{u}$ is the displacement vector field. $T$ is the position-dependent temperature field with a radial profile obtained from BaCo. The coefficients $\lambda, \mu$, and $K$ can be expressed as functions of the Poisson ratio $v$ and the 


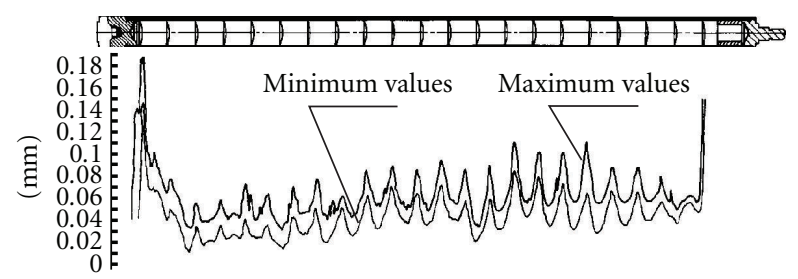

(a)

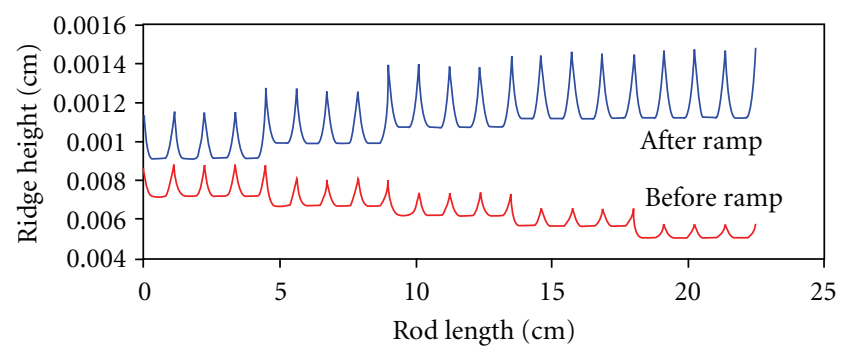

(b)

FIGURE 9: Fuel rod profile of the MOX fuel A.1.3 before and after the power ramp at EOL. (a) Experimental values after the power ramp.

(b) Calculated values before and after ramp.

Young modulus $E$. The thermal expansion coefficient can be obtained from the fractional linear expansion ratio $(\Delta L / L)$,

$$
\frac{\Delta L}{L}=\alpha \cdot\left(T-T_{0}\right)
$$

For $\mathrm{UO}_{2}$ fuel, $v=0.316$. The Young modulus and the fractional linear expansion ratio are temperature dependent. All the material properties were obtained from [9].

The boundary condition for solving (1) is a uniform hydrostatic pressure. For the fuel pellet, this is the gas pressure in the fuel rod, and it is calculated with BaCo.

Once the displacement field $\vec{u}$ is obtained after solving (1) by the finite elements method, the stress tensor field is calculated using (2).

\section{3. $\mathrm{BaCo}+\mathrm{MeCom}$}

BaCo calculates the fuel rod behaviour in a quasibidimensional. It provides the thermal and the stress-strain state of the fuel rod plus the fission gas release, the microstructural changes, and the cracks evolution in the pellet, among others issues. BaCo uses the complete set of models mentioned in $[4,10-12]$. It generates the input data for the MeCom Tools.

The main input data provided by $\mathrm{BaCo}$ to $\mathrm{MeCom}$ are, among others, the geometry of the pellets and the boundary conditions for a particular irradiation time. They are correlated to the fuel rod geometry, its strain-stress state, and to material properties; for example, the pellet and cladding radiuses, the time evolution of the dishing, the pellet and fuel rod temperature profiles, corrections to the thermal conductivity due to densification, gas pressure due to fission gas release, crack pattern formation, and so forth.

The results obtained from the MeCom system are a new 3D pellet geometry and the 3D maps for stresses and strains. Only linear elasticity and thermal expansion are included into the FEM solver. At present, it does not include a way for stress release like creep, cracks opening, and/or plasticity. Then, the resulting strain-stress state from the FEM calculations represents demanding conditions for the fuel pellet behaviour.

\section{A 3D CANDU Fuel Pellet Simulation Approach}

The 3D behaviour of a normal CANDU fuel pellet without chamfers for illustrative purposes is analyzed. A complete analysis of CANDU fuel rod behaviour by using the BaCo code can be found in [5]. The temperature profile of Figure 1 and other parameters calculated with $\mathrm{BaCo}$ are used for a CANDU fuel during high-demanding conditions of operation [5]. The mesh generated with "acdp95" for the finite elements calculation is shown in Figure 3(a). This mesh has more than 15000 elements. The calculated von Misses stresses are shown in Figure 3, where three different views facilitate the analysis. The stress state obtained shows values that exceed the yield stress due to the absence of a mechanism to relax them, like crack opening and/or creep. The highest stresses are located at the shoulders of the pellet where more cracks are usually present.

Figure 4 presents the radial deformations of the CANDU pellet. Here, the highest deformation is achieved at the pellet ends where the ridges are usually present. Figure 4 includes a plot with the radial profile of the pellet. The way of that plot follows the way of the experimental radial profile of CANDU fuels. It is assumed that the cladding profile is the same as the pellet profile. This is a strong assumption but it is sustained for the collapsibility of the CANDU fuels. The height of the ridges has a smaller value than the ones reported in the literature but shows qualitative agreement [1]. Finally, Figure 2 shows a deformed pellet using the previous calculation.

\section{PHWR MOX Experimental Support}

The irradiation of the first prototypes of PHWR MOX fuels fabricated in Argentina began in 1986. These experiments were made in the HFR-Petten reactor, Holland. The six rods were fabricated in the $\alpha$ Facility (CNEA, Argentina) [13-15]. This set of irradiations is included in the IFPE of the OECD [16]. We use one of those irradiations as experimental support for the calculations. An irradiation of PHWR-extended burnup was performed with the MOX fuel rod named A.1.3. The burnup at extraction was $15000 \mathrm{MWd} /$ tonUO 2 , three times the usual burnup at end of life (EOL) of a PHWR NPP, including a demanding power ramp at EOL. The radial power profile during the base irradiation, before the power ramp, presented a maximum value at the bottom of the fuel rod. The temperature profile calculated with the $\mathrm{BaCo}$ code is sketched in Figure 5. The maximum temperature was achieved at the bottom of the rod. The power ramp was performed at the pool side facility of the HFR-Petten reactor. Then, the MOX fuel was flipped, and the maximum values for power and temperature were reached at the opposite side 


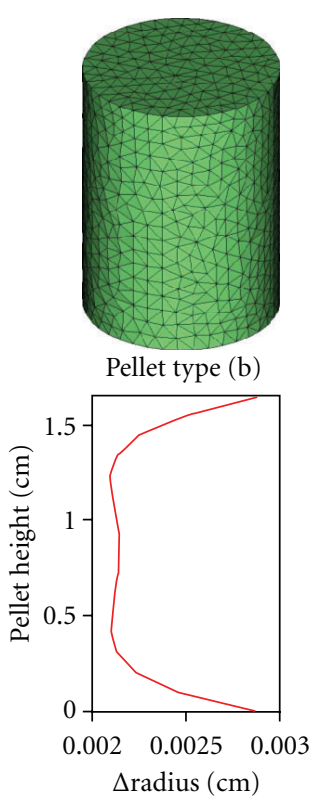

(a)

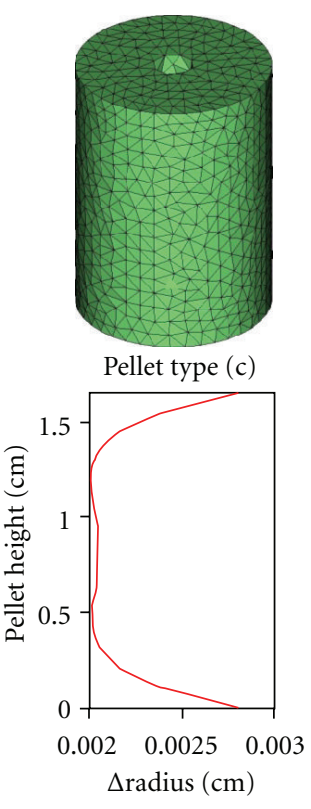

(b)

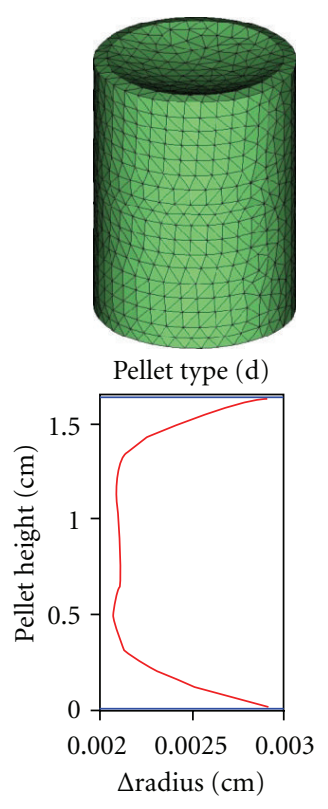

(c)

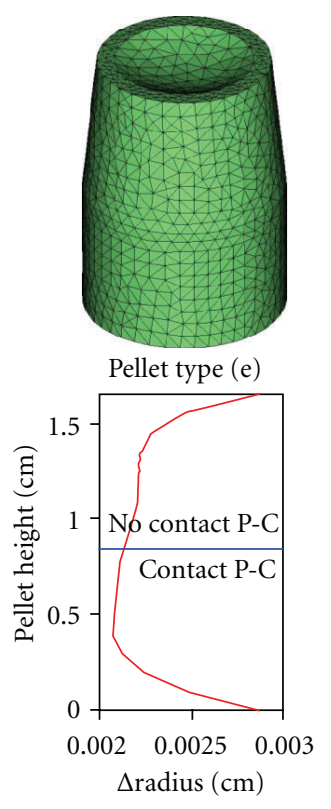

(d)

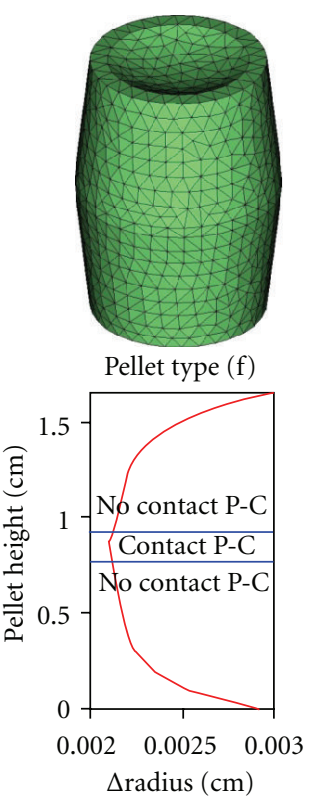

(e)

FIgURE 10: The meshes of experimental CANDU fuel pellets of [1] and their radial deformations. $\Delta R$ is the difference between the present radius and the original one.

of the rod. This situation produced a strong power ramp of $300 \mathrm{~W} / \mathrm{cm}$ in one of the ends of the rod. The new temperature profile is included in Figure 6.

The stress-strain state was calculated for the MOX fuel rod before and after the final ramp by using pellet data, the previous temperature profile as an external field, and the calculated inner pressure as boundary condition. The pellet radial deformations are included in Figures 7 and 8, where the "bamboo" effect and the presence of a small secondary ridge as expected in the five sections of the rod were observed.

Figure 9 includes the fuel rod profile of the MOX rod after the power ramp and the representation of the stack of pellets. It is a strong assumption to correlate the experimental deformations of the MOX fuel with the pellets profile calculated with $\mathrm{BaCo}+\mathrm{MeCom}$ (or PosBaCo). Nevertheless, there is a strong correlation from a qualitative point of view, and the clad wall thickness had only a small effect on the ridge height as was experimentally observed [17].

\section{CANDU Fuel Experimental Support}

In this section, several fuel pellets with real and/or unusual geometric shapes are analyzed. The pellet of Figure 3 will be used in this analysis, and it will be named (a) "normal" pellet, a CANDU fuel pellet with a shoulder and without "chamfers" (Figure 3(a)). Figure 10 shows the following pellets: (b) a flat pellet without dishing, (c) a hollowed pellet without dishing, (d) a standard CANDU fuel pellet, (e) a conic pellet with a dish at the top, and (f) a "barrel" (double conic pellet) with one dish. The radial deformation defined as the difference between the present radius and the original one for each pellet is also shown.
The radial profile of the type (a) pellet (Figure 3(a)) presents more deformation than the "flat" pellet without dishing (type (b) pellet, see Figure 10). This agrees with experimental evidence included in [18].

The presence of "chamfers" in the pellet (see the standard CANDU pellet (d) of Figure 10) disables the presence of the zone of the pellet with the highest deformation. In fact, the chamfers reduce the radial deformation along the entire pellet as we expect by design.

The presence of a central hollow in the pellet (see pellet (c) of Figure 10) reduces the bamboo shape and the radial deformation along the pellet.

The most radical pellets (types (e) and ( $\mathrm{f}$ ) shown in Figure 10) reduce the ridging, but there is no contact situation at the ends of the pellet. These pellets reduce the $\mathrm{UO}_{2}$ content, and they do not keep the concept of a collapsible cladding for CANDU fuels.

These observations agree with the experimental observations reported in $[1,2]$.

\section{An Approach to a 3D Pellet Cracks Simulation}

An approach to a cracked pellet analysis can be initiated with the two cracks defined in Figure 11: (a) a single crack at the top of the pellet and (b) a single crack crossing from the top to the bottom of the pellet. The radial profile of the single-cracked pellet of Figure 11(a) shows a maximum value of the radial deformation close to the crack. The minimum deformation is present in the opposite side of the crack. The case of a full crack of Figure 11(b) presents the maximum deformation close to the crack, but the minimum value is located at $\pm 30^{\circ}$ of the crack. These curves of 

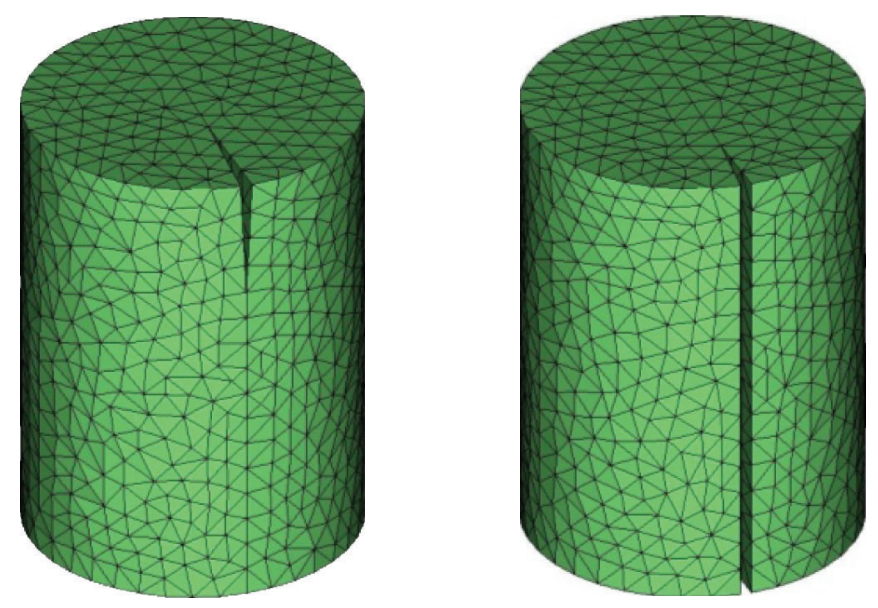

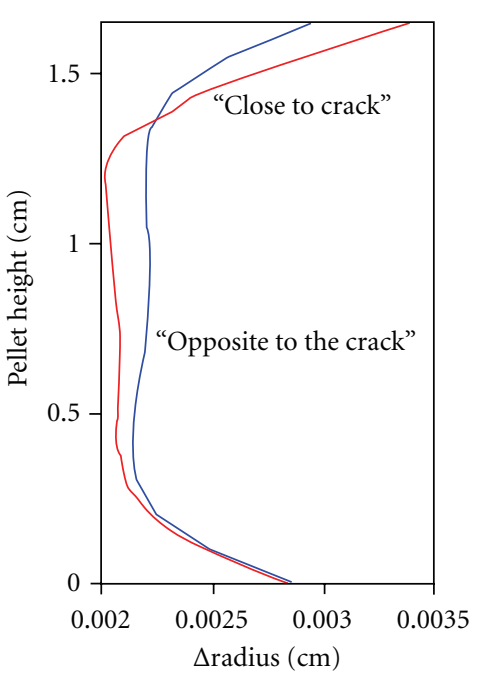

(a)

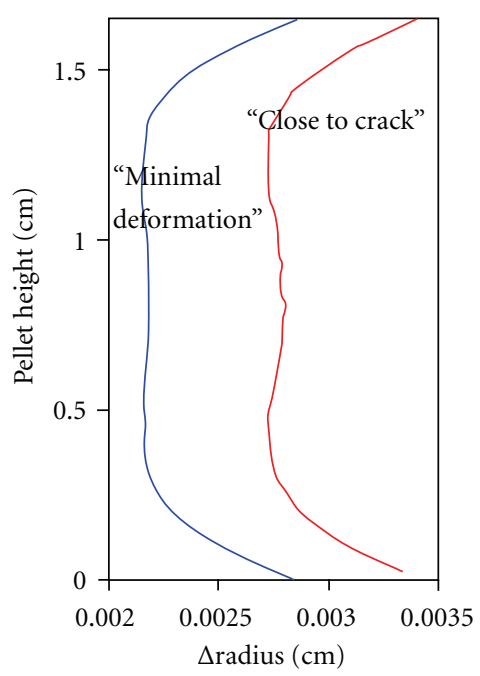

(b)

FIGURE 11: Two types of cracked fuel for stress analysis and its radial profile. (a) Oblique crack. (c) Full vertical crack.

minimum values for the radial deformations look equivalent in both types of cracked pellets. The maximum value of the deformation reaches the same value for both types of cracked pellets. However, the pellet of Figure 11(a) presents the maximum at the top, and there is a strong decrement of its deformation along the height of the pellet. It is clearly shown that the presence of the "real" cracks (similar to the crack of Figure 11(a)) increases the ridging at its location but reduces the deformation along the rest of the pellet. This is in agreement with the previous radial profiles calculated for different pellet type without the presence of cracks where the ridges were underestimated.

Figure 13 shows the von Mises equivalent stress for three cracked pellets similar to the one of Figure 11(a) but with three different crack penetrations. We observe a concentration of stresses at the vertex of the cracks. An effect of stress release due to the presence of the crack is clearly shown. This analysis could be continued with the inclusion of several cracks in the pellet in order to reduce stresses.

\section{Pellet Design}

It was mentioned above that the optimization of pellet geometry can be performed by finding the best $l / d$ relation. This is confirmed by the agreement with several experiments present in the literature $[1,2]$. Figure 12 includes two different pellets with $l / d=0.5$ (Figure $12(\mathrm{a})$ ) and $l / d=1.5$ (Figure 12(b)). It was found that the ridging is reduced when $l / d$ is reduced in perfect agreement with experimental observation. The curve of Figure 14 includes the experimental values and the authors' calculations with different $l / d$ values. There is not a clear correlation between experimental results and BaCo calculations because the experimental evaluation of the fuel ridging was not clearly explained in the measurements performed in the references. However, for a qualitative purpose, we see that the global trends of the measurements of the mean ridge height are the same as the radial deformations of the pellets. The qualitative agreement was extended by varying shoulders and chamfers as it is shown in Figure 14. The increment of $l / d$ over more 

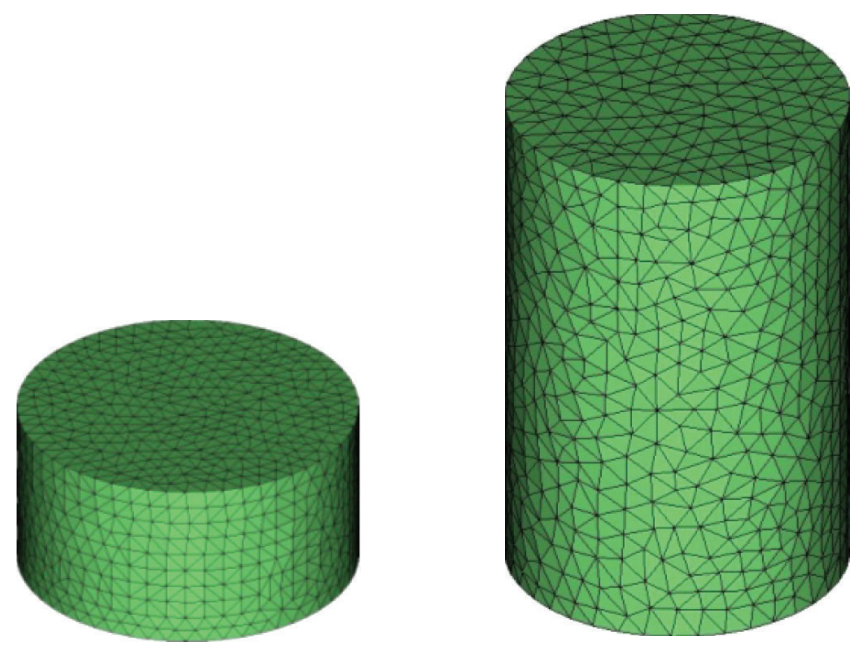

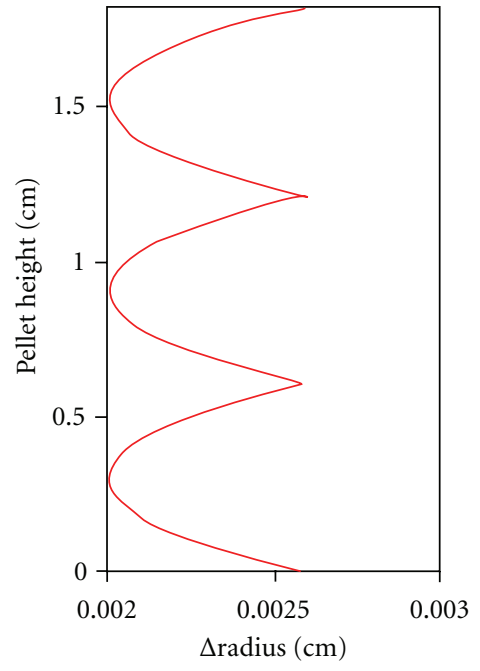

(a)

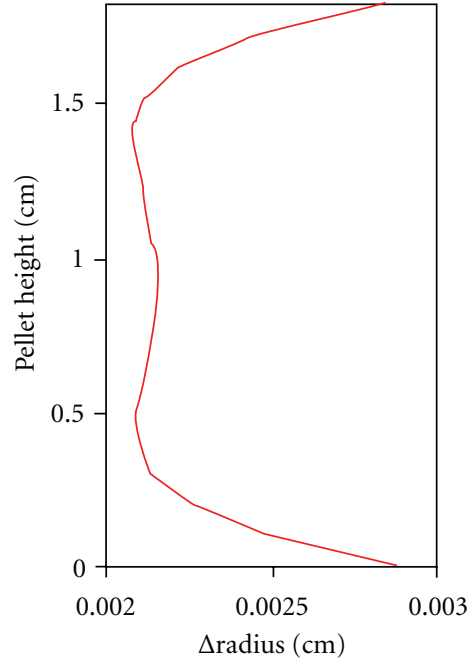

(b)

Figure 12: Meshes of CANDU pellets for the " $l / d$ " analysis. (a) $l / d=0.5$, (b) $l / d=1.5$.

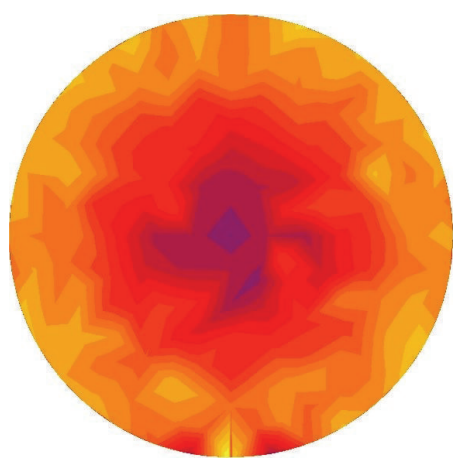

(a)

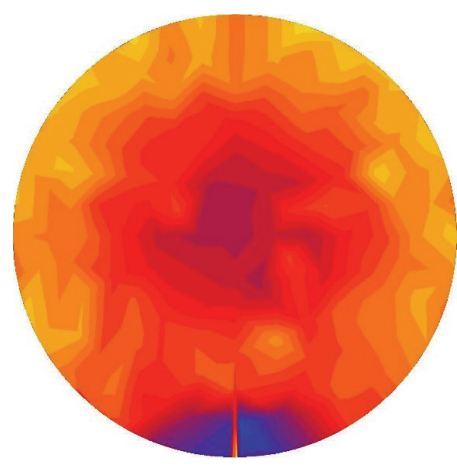

(b)

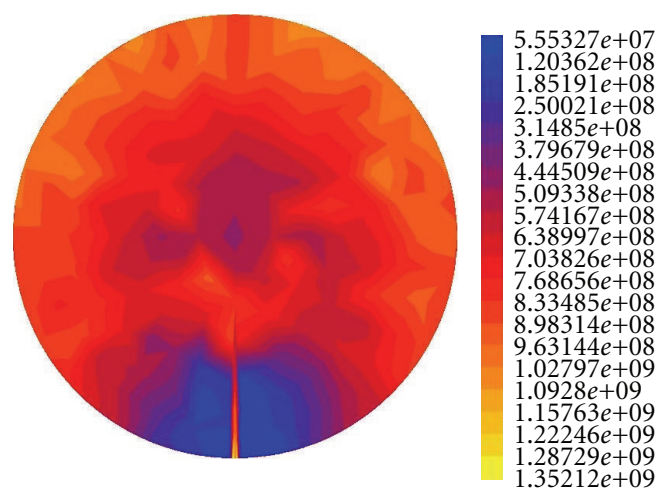

(c)

FIgURE 13: Top view of the von Mises equivalent stress for three cracked pellets type with different values of penetration. 


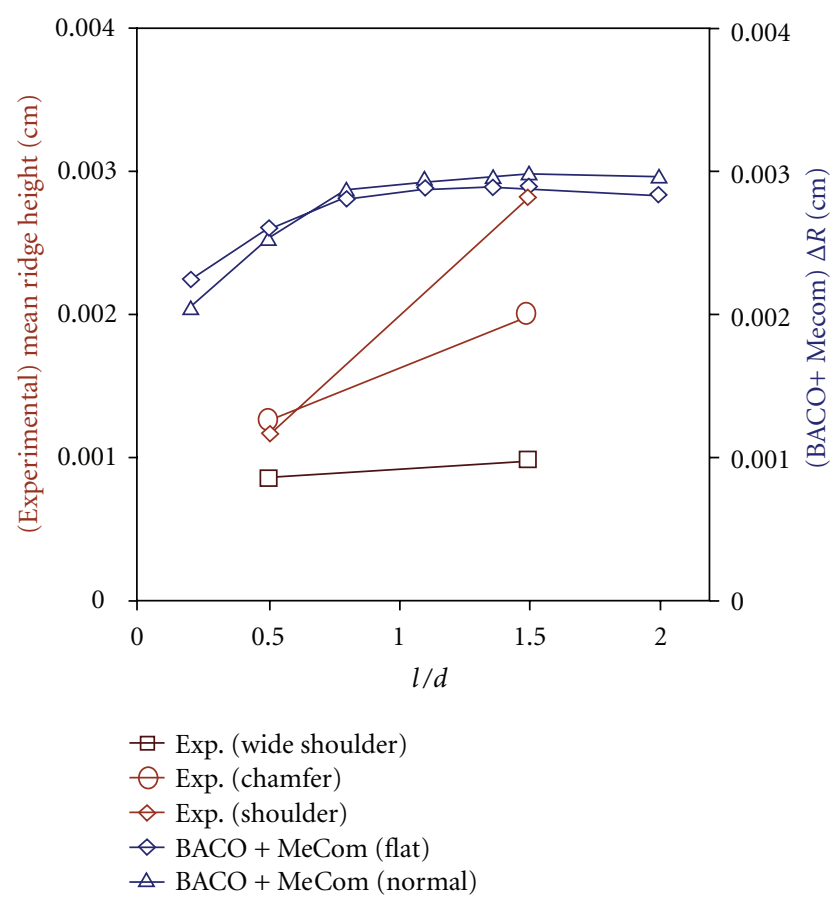

Figure 14: Correlation between experimental mean ridge height and radial deformation $(\Delta R)$ calculated by varying the " $l / d$ " relation.

than 1.3 produces the maximum value of deformation. The decrement of $l / d$ produces a convergence to the lowest values for the radial deformation. These trends are present in all the BaCo calculations.

\section{Conclusions}

The symbiosis between BaCo and MECOM tools (PosBaCo) by using CANDU, CARA, and PHWR MOX fuels as input data was shown. At present, only linear elasticity in the $3 \mathrm{D}$ evaluation and all the set of modelling of BaCo was included. The results show good agreement between experimental data and calculations, particularly for the pellet radial profile after irradiation. The coupling of BaCo and MECOM tools constitutes a powerful system for the analysis and design of nuclear fuel pellets taking into account very different shapes of the fuel pellets, the best combination of $l / d$, and the dimensioning of dishing, shoulder, and chamfers. The influence of the cracks was established and appointed as a way to increase ridging and to release stresses. We should mention: (a) the reduction of the deformation of hollowed pellet, (b) the absence of ridging when conic shapes are used for the pellets, (c) the increment of ridging when a dishing is present in the pellet, (d) the reduction of ridging due to chamfers, and (e) the trends of radial deformation by the variation of $l / d$, as interesting examples by using PosBaCo. Innovative or unusual pellet shapes can be analyzed by using these "ad hoc" tools against the actual tendency to use commercial software adapted for nuclear applications. We emphasize the economical aspect of these tools, where a few code runs can reduce the number of experimental irradiations in an expensive programme and provide a frame for the analysis of the experiments.

\section{Abbreviations}

MeCom: Mecánica computational (Spanish expression for "computational mechanics")

BaCo: Barra combustible (Spanish expression for "fuel rod")

BOL: Beginning of life

CARA: Combustible avanzado para reactores Argentinos (advanced fuel for argentine reactors)

CANDU: Canada deuterium uranium

PHWR: Pressurised heavy water reactor

MOX: $\quad$ Mixed oxide fuel

PCMI: Pellet-cladding mechanical interaction

PCI-SCC: Pellet cladding interaction stress corrosion cracking

PWR: $\quad$ Pressurised water reactor

BWR: Boiling water reactor

CNEA: Comisión Nacional de Energía Atómica (Spanish expression for "Atomic Energy National Commission of Argentina")

3D: $\quad$ Three dimensional

DAEE: Diseños avanzados y evaluación económica (Spanish expression for "advanced design and economics assessment")

FEM: $\quad$ Finite element method

CAB: Bariloche Atomic Centre

IFPE: International fuel performance of experiments database

OECD: Organisation for Economic Co-operation and Development

EOL: $\quad$ End of life

NPP: $\quad$ Nuclear power plant

HFR: High flux reactor.

\section{Acknowledgments}

The authors thank Dr. E. Dari and Dr. G. Buscaglia who kindly made available to us the MeCom tools.

\section{References}

[1] I. J. Hastings, T. J. Carter, R. da Silva, P. J. Fehrenbach, D. G. Hardy, and J. Wood, "CANDU fuel performance: influence of fabrication variables," in Proceedings of the International Seminar on Heavy Water Reactor Fuel Technology, vol. 250, IAEA-CNEA, San Carlos de Bariloche, Argentina, June 1983.

[2] T. J. Carter, "Experimental investigation of various pellet geometries to reduce strains in zirconium alloy cladding," Nuclear Technology, vol. 45, no. 2, pp. 166-176, 1979.

[3] F. Bentejac and N. Hourdequin, "TOUTATIS, an Application of the Cast3M Finite Element Code Three-dimensional Modelling," Les Journées de Cadarache 2004: International Seminar on Pellet-Clad Interaction in Water Reactor Fuels 
(PCI-2004)" organized by CEA Cadarache/DEN/DEC In cooperation with OECD/NEA, IAEA, EDF, FRAMATONE ANP, COGEMA, 9 to 11 of March 2004, Aix en Provence, France.

[4] A. C. Marino, E. J. Savino, and S. Harriague, "BACO (BArra COmbustible) code version 2.20: a thermo-mechanical description of a nuclear fuel rod," Journal of Nuclear Materials, vol. 229, pp. 155-168, 1996.

[5] M. De Oliveira, A. C. Salgado, R. A. Feijóo, M. J. Vénere, and E. A. Dari, "An object oriented tool for automatic surface mesh generation using the advancing front technique," Latin American Applied Research, vol. 27, no. 1-2, pp. 39-49, 1997.

[6] G. Buscaglia et al., "Un programa general de elementos finitos en paralelo," in Proceedings of the 6th Congreso Argentino de Mecánica Computacional (MECOM '99), Mendoza, Argentina, September 1999.

[7] P. D. Zavattieri, G. C. Buscaglia, and E. A. Dari, "Finite element mesh optimization in three dimensions," Latin American Applied Research, vol. 26, no. 3-4, pp. 233-236, 1996.

[8] E. Dari et al., "A parallel general purpose finite element system," in Proceedings of the 9th SIAM Conference on Parallel Processing for Scientific Computing, San Antonio, Tex, USA, March 1999.

[9] MATPRO-Version 11, A Handbook of Material Properties for Use in the Analysis of Light Water Reactor Fuel Rod Behaviour, NUREG/CR-0497, 1970.

[10] A. C. Marino and E. J. Savino, "Sensitivity analysis applied to nuclear fuel performance related to fabrication parameters and experiments," in Proceedings of the 14th International Conference on Structural Mechanics in Reactor Technology, Lyon, France, August 1997.

[11] A. C. Marino, "Computer simulation of the behaviour and performance of a CANDU fuel rod," in Proceedings of the 5th International Conference on CANDU Fuel, Toronto, Canada, September 1997.

[12] A. C. Marino, "Crack and dishing evolution models and PCISCC considerations for fuel pellets in a quasi bidimensional environment," Les Journées de Cadarache 2004: International Seminar on Pellet-Clad Interaction in Water Reactor Fuels (PCI-2004)" organized by CEA Cadarache/DEN/DEC In cooperation with OECD/NEA, IAEA, EDF, FRAMATONE ANP, CO4GEMA, 9 to 11 of March 2004, Aix en Provence, France.

[13] A. C. Marino, E. Pérez, and P. Adelfang, "Argentine nuclear fuels MOX irradiated in the petten reactor, experience analysis with the BACO code," in Proceedings of the Technical Committee Meeting on Water Reactor Fuel Element Modelling at High Burnup and Its Experimental Support, vol. 957, IAEATECDOC, Windermere, UK, September, 1994.

[14] A. C. Marino, E. Pérez, and P. Adelfang, "Irradiation of Argentine MOX fuels. Post irradiation results and analysis," in Proceedings of the Technical Committee Meeting on Recycling of Plutonium and Uranium in Water Reactor Fuel, vol. 941, IAEATECDOC, Windermere, UK, July 1995.

[15] A. C. Marino, E. Pérez, and P. Adelfang, "Irradiation of Argentine $(\mathrm{U}, \mathrm{Pu}) \mathrm{O}$ MOX fuels. Post-irradiation results and experimental analysis with the BACO code," Journal of Nuclear Materials, vol. 229, pp. 169-186, 1996.

[16] J. A. Turnbull, J. C. Killeen, and E. Sartori, "Experimental Data on PCI and PCMI within the IFPE Database," Les Journées de Cadarache 2004: International Seminar on Pellet-Clad Interaction in Water Reactor Fuels (PCI-2004)" organized by CEA Cadarache/DEN/DEC In co-operation with OECD/NEA, IAEA, EDF, FRAMATOME ANP, CO4GEMA, 9 to 11 of March 2004, Aix en Provence, France.
[17] U. Graziani, "Experimental Data Following an $85 \%$ Increase of the IFA-509 Assembly Power at $3800 \mathrm{MWd} / \mathrm{tUO}_{2}$," HPR229 EHPG Hankø, Norway, June 1979.

[18] E. Kolstad et al., "Review of Test Results on Gap Closure Behaviour and Mechanical Interaction Effects in the HBWR," HWR-89 May 1983. 

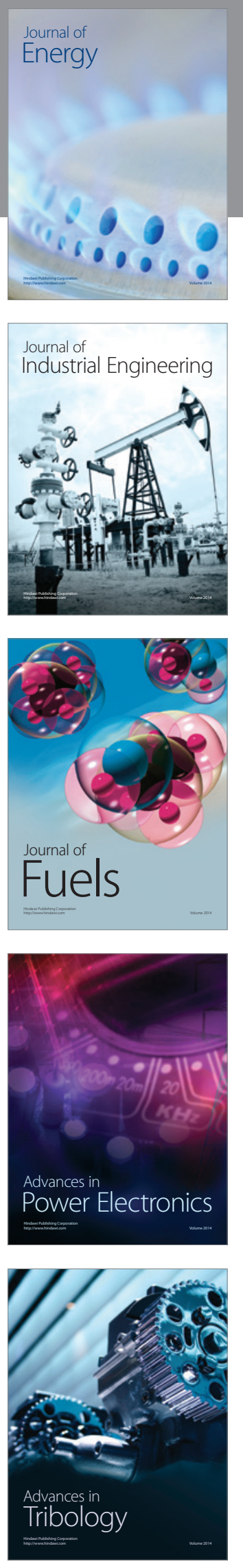
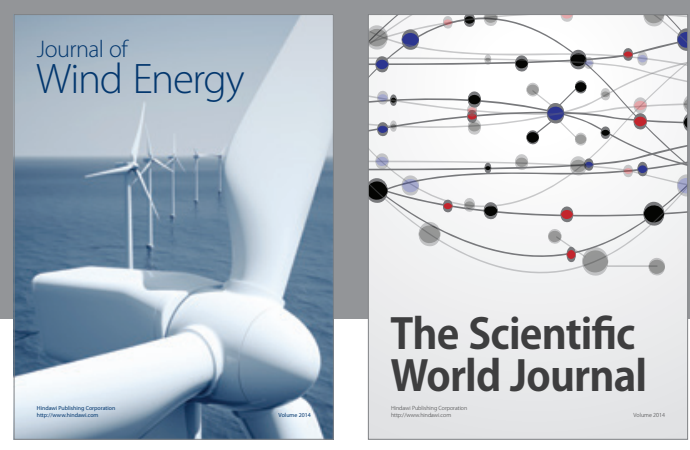

The Scientific World Journal

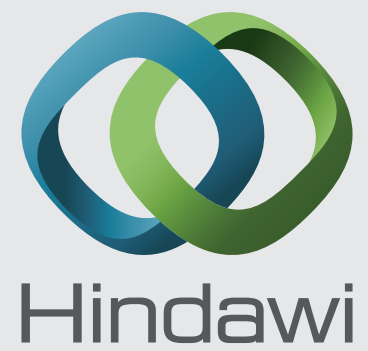

Submit your manuscripts at http://www.hindawi.com
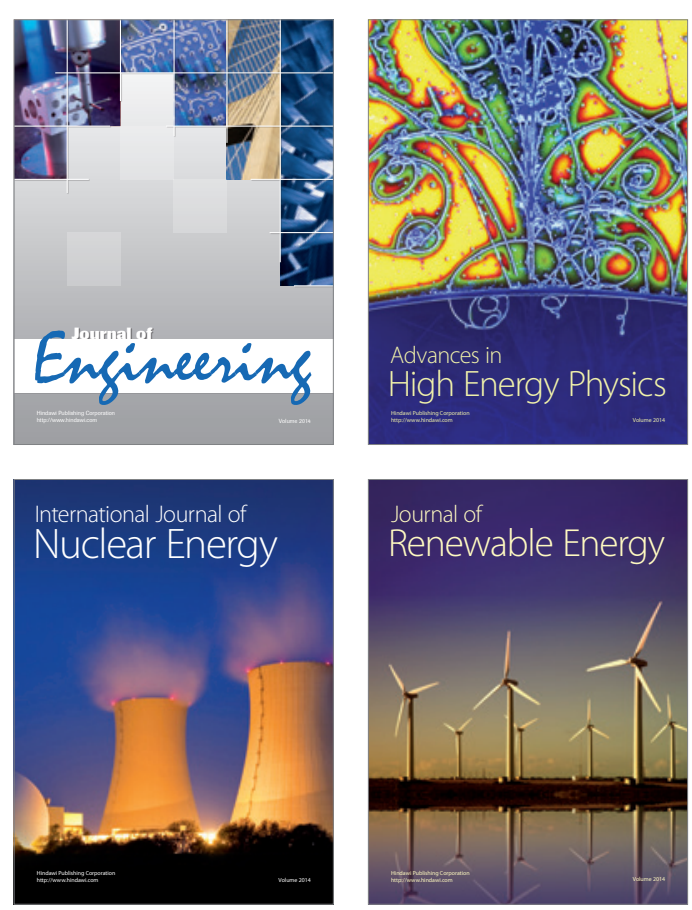

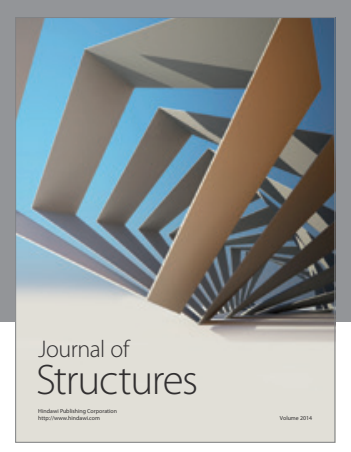

Rotating
Mechinery
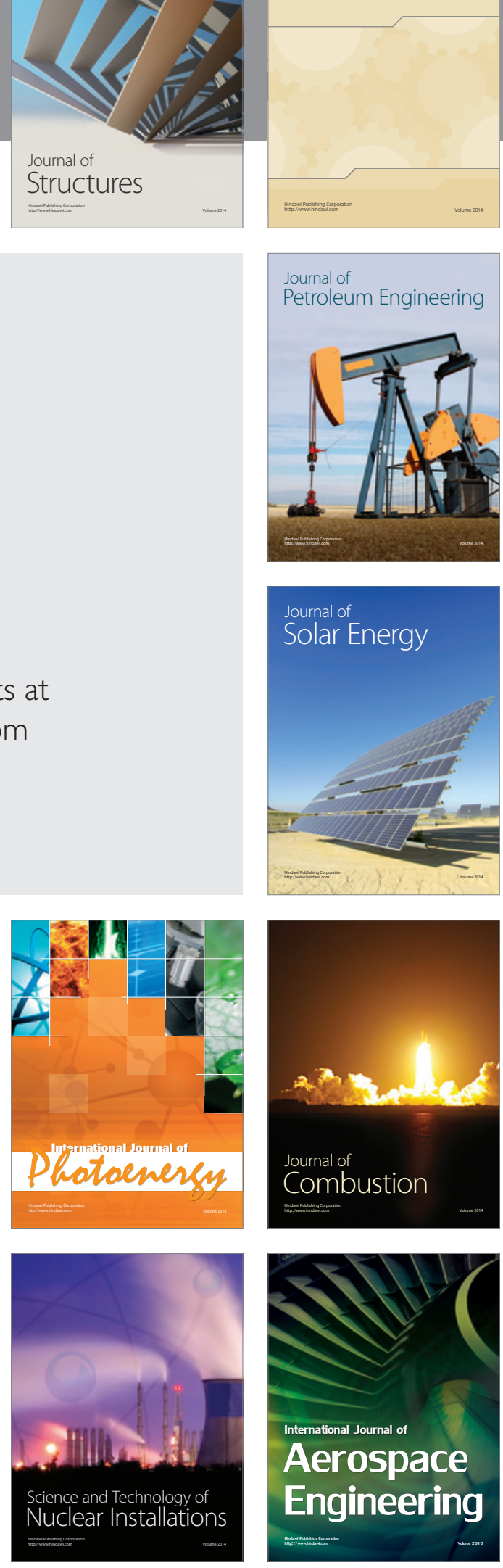